\title{
Implementasi Program GERMAS pada Lansia di Wilayah Kerja Puskesmas Margoyoso II
}

\author{
Implementation of the GERMAS Program for the Elderly in the Area of the Margoyoso II \\ Community Health Center
}

\author{
Merry Tiyas Anggraini ${ }^{1 *}$, Aisyah Lahdji ${ }^{1}$, Nina Anggraeni Noviasari ${ }^{1}$, Nabila Min Amrina Rosyada ${ }^{2}$ \\ ${ }^{\mathbf{1}}$ Staf Pengajar Fakultas Kedokteran Universitas Muhammadiyah Semarang \\ ${ }^{2}$ Mahasiswi Fakultas Kedokteran Universitas Muhammadiyah Semarang \\ *Penulis korespondensi. Merry Tiyas Anggraini. Email: merry.tyas@unimus.ac.id \\ Telp: +62 822593750
}

\begin{abstract}
ABSTRAK
Pendahuluan: Program GERMAS yang digalakkan pemerintah meliputi kegiatan melakukan aktifitas fisik, mengonsumsi sayur dan buah, tidak merokok, tidak mengonsumsi alkohol, memeriksa kesehatan secara rutin, membersihkan lingkungan, dan menggunakan jamban. Permasalahan yang terjadi di wilayah kerja Puskesmas Margoyoso II adalah tingginya jumlah lansia dan belum ada laporan tentang pelaksanaan program GERMAS pada lansia dengan baik. Meningkatnya jumlah lanjut usia akan menimbulkan masalah kesehatan jika tidak dilakukan upaya pelayanan kesehatan yang baik. Tujuan penelitian ini adalah untuk menjelaskan gambaran implementasi program GERMAS pada lansia di wilayah kerja Puskesmas Margoyoso II.

Metode: Penelitian ini dilakukan di Desa Sidomukti wilayah kerja Puskesmas Margoyoso II pada bulan JanuariFebruari tahun 2021 menggunakan desain penelitian observasional yang dianalisis secara deskriptif. Populasi adalah lansia di Desa Sidomukti di wilayah kerja Puskesmas Margoyoso II dengan besar sampel 43 orang. Pengambilan sampel dengan teknik consecutive sampling. Kriteria inklusi dalam penelitian ini adalah lansia berumur $\geq 60$ tahun yang sehat dan kooperatif, serta bersedia menjadi responden. Kriteria eksklusinya adalah lansia yang mengisi kuesioner tidak lengkap.

Hasil: Mayoritas responden sebesar 51,2\% sudah cukup baik dalam melakukan aktifitas fisik, 79,1\% sudah baik dalam mengonsumsi sayur dan buah, 55,8 \% sudah cukup baik dalam kegiatan memeriksakan kesehatan rutin. 86\% tidak merokok, 95,3\% tidak mengonsumsi alkohol, 100\% telah rutin membersihkan lingkungan, dan 97,7\% sudah menggunakan jamban,
\end{abstract}

Kesimpulan: Implementasi Program GERMAS pada lansia di wilayah kerja Puskesmas Margoyoso II sudah berjalan dengan baik.

Kata kunci: GERMAS, lansia, aktivitas, cek kesehatan

\section{ABSTRACT}

Introduction : GERMAS program can be done by doing physical activity, eating vegetables and fruit, not smoking, not consuming alcohol, do medical check-up regularly, cleaning the environment, and using a latrine. The problem that occurs in working area of Puskesmas Margoyoso II is high number of elderly and there has been no report of the implementation of the GERMAS program in the elderly properly. The increasing number of elderly people will cause health problems if good health services are not implemented. The purpose of this study was to explain the description of the implementation of the GERMAS program in the elderly in the working area of Puskesmas Margoyoso II

Method: This research was conducted in Sidomukti Village, the working area of Puskesmas Margoyoso II in JanuaryFebruary 2021 using an observational research design that was analyzed descriptively. The population was the elderly in Sidomukti Village in the working area of Puskesmas Margoyoso II with a sample size of 43 people. Sampling technique used the consecutive sampling. The inclusion criteria in this study were elderly people aged $\geq 60$ years who were healthy and cooperative and willing to become respondents. The exclusion criteria were elderly people who filled out an incomplete questionnaire.

Result: The majority of respondents, 51.2\%, were quite good at doing physical activities, $79.1 \%$ were good at consuming vegetables and fruit, 55.8\% were good enough in medical check-up, $86 \%$ did not smoke, $95.3 \%$ did not consume alcohol, 100\% have cleaned the environment routinely, and $97.7 \%$ have used the latrine.

Conclusion: The implementation of the GERMAS program for the elderly in the working area of Puskesmas Margoyoso II has gone well. 
Key Words: GERMAS, elderly, activity, medical-check up

\section{PENDAHULUAN}

Program GERMAS (Gerakan Masyarakat Hidup Sehat) adalah gerakan bersama yang mengutamakan kegiatan promotif dan preventif tanpa mengesampingkan kegiatan kuratif-rehabilitatif dengan melibatkan seluruh lapisan masyarakat dalam mengkampanyekan paradigma sehat. Program GERMAS meliputi kegiatan melakukan aktifitas fisik, mengonsumsi sayur dan buah, tidak merokok, tidak mengonsumsi alkohol, memeriksa kesehatan secara rutin, membersihkan lingkungan, dan menggunakan jamban. ${ }^{1,2}$

Permasalahan yang terjadi adalah masyarakat belum melakukan GERMAS dengan baik. Data Riskesdas pada tahun 2018 perilaku kesehatan masyarakat yang terjadi adalah penduduk $\geq 10$ tahun yang merokok $(28,8 \%)$, konsumsi minuman beralkohol (3,3\%), aktivitas fisik kurang (33,5\%), konsumsi buah atau sayur kurang pada penduduk $\geq 5$ tahun sebesar $(95,5 \%))^{3,4}$ Seiring bertambahnya usia manusia, maka kemampuan tubuh untuk menghadapi berbagai perubahan yang mengganggu homeostasis juga semakin berkurang. Laju kematian terhadap banyak penyakit terus meningkat, terutama karena menurunnya kemampuan lanjut usia berespons terhadap stress baik stress fisik ataupun fisiologik. ${ }^{5}$

Persentase lansia di Indonesia meningkat dua kali lipat dalam hampir lima dekade (1971-2019) menjadi 9,6\% (25-jutaan). ${ }^{6}$ Berdasarkan data BPS Kabupaten Pati tahun 2017, kelompok lansia di atas 65 tahun sebesar 108.788 jiwa, hal ini mengalami peningkatan jika dibandingkan tahun 2015 sebesar 105.405 jiwa. Kecamatan Margoyoso menjadi salah satu kecamatan dengan kepadatan penduduk di atas rata-rata yaitu sebesar 73.582 di tahun $2017 .^{7}$ Meningkatnya jumlah lanjut usia akan menimbulkan masalah kesehatan jika tidak dilakukan upaya pelayanan kesehatan yang baik karena lansia sendiri telah mengalami perubahan dari yang dulunya dewasa sehat menjadi seorang yang rentan atau lemah.

Jumlah lansia di wilayah kerja Puskesmas Margoyoso II bulan Desember 2019 sebanyak 4.389 orang. Gambaran pelaksanaan GERMAS di Puskesmas Margoyoso II meliputi adanya menu GERMAS yang diberikan tiap 2 minggu sekali di hari sabtu, selain itu menginformasikan ke desa binaan untuk memberikan menu GERMAS jika ada suatu pertemuan atau rapat, menjalankan aktivitas fisik seperti adanya senam tiap sabtu pagi. Adapun program GERMAS untuk kesehatan lansia, yaitu dengan adanya posyandu lansia yang terdapat di masingmasing desa binaan. Lansia dipandu untuk melakukan senam lansia, pola makan yang sehat serta melakukan pemeriksaan kesehatan secara rutin. Desa Sidomukti merupakan salah satu desa binaan di wilayah kerja Puskesmas Margoyoso II dengan jumlah lansia 240 orang di tahun 2019 namun hingga saat ini belum ada laporan tentang pelaksanaan program GERMAS pada lansia dengan baik.

\section{METODE}

Penelitian ini dilakukan di Desa Sidomukti wilayah kerja Puskesmas Margoyoso II pada bulan Januari-Februari tahun 2021. Penelitian ini merupakan penelitian observasional yang dianalisis secara deskriptif. Populasi penelitian ini adalah lansia di Desa Sidomukti di wilayah kerja Puskesmas Margoyoso II dengan besar sampel 43 orang. Pengambilan sampel dengan teknik consecutive sampling. Kriteria inklusi dalam penelitian ini adalah lansia berumur $\geq$ 60 tahun yang sehat dan kooperatif, serta bersedia menjadi responden. Kriteria Eksklusinya adalah lansia yang mengisi kuesioner tidak lengkap. 


\section{HASIL DAN PEMBAHASAN}

\section{Hasil}

Tabel 1. Karakteristik lansia di wilayah kerja Puskesmas Margoyoso II

\begin{tabular}{llll}
\hline Karakteristik & Kategori & $\mathrm{f}$ & $\%$ \\
\hline Jenis Kelamin & Laki-laki & 17 & 39,5 \\
& Perempuan & 26 & 60,5 \\
Pendidikan & Tidak sekolah & 6 & 14,0 \\
\multirow{3}{*}{ Pekerjaan } & SD & 30 & 69,8 \\
& Tidak bekerja & 10 & 23,3 \\
& Buruh & 5 & 11,6 \\
& Petani & 21 & 48,8 \\
& Wiraswasta & 4 & 9,3 \\
\hline
\end{tabular}

Tabel 2. Implementasi Program GERMAS pada lansia di wilayah kerja Puskesmas Margoyoso II

\begin{tabular}{lcc}
\hline \multicolumn{1}{c}{ Kegiatan GERMAS } & $\mathrm{f}$ & $\%$ \\
\hline Melakukan aktivitas fisik & 4 & 9.3 \\
Kurang & 22 & 51.2 \\
Cukup & 17 & 39.5 \\
Baik & 1 & \\
\hline Mengkonsumsi buah dan sayur & 8 & 2.3 \\
Kurang & 34 & 18.6 \\
Cukup & & 79.1 \\
Baik & 19 & 44.2 \\
\hline Memeriksakan kesehatan secara rutin & 9 & 20.9 \\
Kurang & 15 & 34.9 \\
Cukup & & \\
Baik & 4 & 9.3 \\
\hline Kebiasaan tidak merokok & 2 & 4.7 \\
Kurang & 37 & 86.0 \\
Cukup & & \\
Baik & 2 & 4.7 \\
\hline Kebiasaan tidak mengkonsumsi alkohol & 41 & 95.3 \\
Kurang & & \\
Baik & 43 & 100 \\
\hline Membersihkan lingkungan & 0 & 0 \\
Ya & & \\
Tidak & 42 & 97,7 \\
\hline Penggunaan jamban & 1 & 2.3 \\
Ya & &
\end{tabular}




\section{Pembahasan}

\section{Melakukan aktivitas fisik}

Hasil penelitian ini menunjukkan bahwa mayoritas responden telah melakukan aktivitas fisik. Ada beberapa faktor yang dapat mempengaruhi aktifitas fisik antara lain umur, jenis kelamin, pekerjaan, pendidikan. Melakukan akifitas fisik terbukti mencegah risiko terjadinya penyakit degeneratif. ${ }^{8}$

\section{Mengkonsumsi buah dan sayur}

Hasil penelitian ini menunjukan bahwa mayoritas responden telah rutin konsumsi buah dan sayur. Angka kecukupan konsumsi buah dan sayur yang direkomendasi yaitu 300-400 gram perorang perhari. ${ }^{9}$ Menurut data hasil Risekesdas dan Studi Diet Total (SDT) pada tahun 2013 konsumsi buah dan sayur penduduk di Indonesia masih sangat rendah. Hasil penelitian lain diketahui bahwa hampir tidak ada masyarakat yang mengkonsumsi buah secara rutin setiap hari, akan tetapi mayoritas masyarakat mengkonsumsi sayur hampir setiap hari. ${ }^{10}$

Penelitian lain menunjukan bahwa hampir seluruh masyarakat di Indonesia telah rutin konsumsi sayur $(94,8 \%)$ namun masih sangat sedikit yang rutin mengkonsumsi buah $(33,2 \%){ }^{11}$ Konsumsi buah dan sayur telah terbukti dapat mengurangi resiko terjadinya berbagai jenis penyakit. Buah dan sayur juga dapat menjadi sumber energi alami yang dibutuhkan oleh tubuh.

\section{Memeriksakan kesehatan secara rutin}

Hasil penelitian ini menunjukkan bahwa mayoritas responden belum memeriksakan kesehatan secara rutin. Sebagian besar responden tidak melakukan pemeriksaan Kesehatan secara rutin karena mereka khawatir apabila ternyata hasilnya tidak baik, Sebagian responden menuaytakan alasan tidak melakukan pemeriksaan kesehatan karena biaya yang harus dibayarkan. Faktor lain yang mempengaruhi juga mempengaruhi kesadaran mereka untuk melakukan pemeriksaan kesehatan secara rutin adalah tingkat pendidikan. $^{12}$ Faktor lain yaitu keterbatasan waktu karena pekerjaan juga mempengaruhi masyarakat untuk melakukan pemeriksaan kesehatan secara rutin.

\section{Kebiasaan tidak merokok}

Hasil penelitian ini menunjukkan bahwa mayoritas responden tidak merokok. Kebiasaaan merokok saat ini menjadi tantangan para tokoh penggiat pelayanan promosi kesehatan. Promosi kesehatan adalah proses untuk mendorong masyarakat agar meningkatkan derajat kesehatannya, karena sekarang ini rokok telah menjadi faktor risiko utama penyakit tidak menular di Indonesia. 13,14

\section{Kebiasaan tidak mengkonsumsi alcohol}

Hasil penelitian ini menunjukkan bahwa mayoritas responden tidak mengkonsumsi alkohol. Kebiasaan mengkonsumsi alkohol terbukti sangat merugikan kesehatan seseorang. Konsumsi alkohol yang terlalu banyak dapat menurunkan kemampuan otak dalam hal berpikir dan menimbulkan gangguan perilaku. Konsumsi minuman beralkohol yang berlebihan, dapat mengakibatkan sesorang dapat terjadi kehilangan kesadaran, kejang, serta menyebabkan penyakit yang serius hingga bisa mengakibatkan kematian. ${ }^{15}$

\section{Membersihkan lingkungan}

Hasil penelitian ini menunjukkan bahwa seluruh responden rutin membersihkan lingkungan sekitar rumah mereka. Salah satu implementasi kegiatan Germas yaitu peningkatan kebersihan lingkungan, antara lain kondisi rumah yang nyaman dan sehat. ${ }^{16}$

\section{Penggunaan jamban}

Hasil penelitian ini menunjukkan bahwa mayoritas responden sudah menggunakan 
jamban untuk buang air besar. Syarat rumah sehat antara lain : adanya sarana air bersih, adanya kamar mandi dan jamban, adanya saluran pembuangan limbah, adanya septic tank, jumlah penghuni yang tidak padat, pencahayaan dan ventilasi yang cukup dan bangunan yang kokoh. ${ }^{15,16}$

Keterbatasan dari penelitian ini adalah pengambilan data dengan menggunakan kuesioner yang terkadang menyebabkan jawaban subyek penelitian tidak menunjukkan keadaan yang sebenarnya sehingga dapat menyebabkan efek bias.

\section{KESIMPULAN DAN SARAN}

\section{Kesimpulan}

Implementasi Program GERMAS pada lansia di wilayah kerja Puskesmas Margoyoso II sudah berjalan dengan baik.

\section{Saran}

Masyarakat khususnya lansia diharapkan aktif melakukan Gerakan Masyarakat Hidup Sehat (GERMAS) untuk meningkatkan kualitas hidup dan kesehatan karena masih ada lansia yang kurang aktif dalam melaksanakan GERMAS. Bagi peneliti selanjutnya diharapkan dapat melakukan penelitian lanjutan dengan metode lain seperti metode kualitatif agar dapat memperoleh informasi secara mendalam.

\section{DAFTAR PUSTAKA}

1. Kementerian Kesehatan Republik Indonesia. GERMAS wujudkan indonesia sehat; 2016.

2. Departemen Kesehatan Republik Indonesia. UU nomor 36 tahun 2009 tentang kesehatan. Jakarta : Departemen Kesehatan; 2009.

3. Badan penelitian dan pengembangan kesehatan. Hasil utama riskesdas 2018. Kementerian Kesehatan RI; 2018.
4. Badan Pusat Statistik Provinsi Jawa Tengah. Statistik pendidikan jawa tengah; 2018.

5. Setiati S, Harimurti K, Govinda A. Proses menua dan implikasi klinisnya. Jakarta: Badan Penerbit Fakultas Kedokteran Universitas Indonesia p.757-933.

6. Maylasari I, Rachmawati Y, Wilson H, Nugroho SW, Sulistyowati NP, Dewi FWR. Statistik penduduk lanjut usia 2019. Jakarta: Badan Pusat Statistik; 2019.

7. Dinas Kesehatan Kabupaten Pati. Profil kesehatan kabupaten pati tahun 2018. Pati: Dinas Kesehtan Kabupaten Pati; 2018.

8. Hastuti NP, Susanti Y. Gambaran pelaksanaan kegiatan gerakan masyarakat hidup sehat (GERMAS). Jurnal Ilmiah Permas: Jurnal Ilmiah STIKES Kendal. 2019;9(2): 141-8.

9. Kementerian Kesehatan Republik Indonesia. GERMAS - Gerakan masyarakat hidup sehat; 2017.

10. Siti M, Kusyogo C, Syamsulhuda BM. Identifikasi faktor-faktor perilaku hidup bersih dan sehat. Jurnal Kesehatan Masyarakat. 2016 Oktober;4(5): 389395.

11. Hermina, Prihatini S. Gambaran konsumsi sayur dan buah penduduk indonesia dalam konteks gizi seimbang: analisis lanjut survai konsumsi makanan individu (SKMI). Buletin Penelitian Kesehatan. 2014;44(3): 205-218.

12. Evi G. Peran posyandu dalam masyarakat untuk hidup sehat. Mataram News. 2017 Oktober 2017. Available from: URL: HIPERLINK:

https://mataramnews.co.id/14614/peranposyandu-vital-ketika-sadarkanmasyarakat-untuk-hidup-sehat/

13. Pinasih A. 2018 Praktik GERMAS (gerakan masyarakat hidup sehat) 2017 Pada lansia di puskesmas jenggawah kabupaten jember. [Skripsi]. Universitas Jember. Jawa Timur.

14. Tedi, Fadly, Ridho R. Hubungan program germas terhadap kebiasaan hidup 
masyarakat yang telah dan belum mendapatkan sosialisasi di wilayah kerja puskesmas kecamatan sukarame palembang. Jurnal Kesehat Poltekkes Palembang. 2018;13(1): 54-60.

15. Tumurang, Marjes N. Promosi kesehatan. Sidoarjo. Indomedia Pustaka: 2018.

16. Wicaksono, A.A. Menciptakan rumah sehat. Penebar Swadaya: Depok. 2009. 